\title{
Implementing population health management: an international comparative study
}

A study in population health management

\author{
Betty Steenkamer
}

School of Social and Behavioral Sciences, Tilburg University, Tilburg, Netherlands

Esther de Weger and Hanneke Drewes

Department of Prevention and Health Services, Center for Nutrition, National Institute for Public Health and the Environment, Bilthoven, Netherlands Kim Putters

Erasmus School of Health Policy \& Management (ESHPM), Erasmus University, Rotterdam, Netherlands, and

Hans Van Oers and Caroline Baan

National Institute for Public Health and the Environment, Bilthoven, Netherlands and School of Social and Behavioral Sciences, Tilburg University, Tilburg, Netherlands

\begin{abstract}
Purpose - The purpose of this paper is to gain insight into how population health management (PHM) strategies can successfully integrate and reorganize public health, health care, social care and community services to improve population health and quality of care while reducing costs growth, this study compared four large-scale transformation programs: Greater Manchester Devolution, Vancouver Healthy City Strategy, Gen-H Cincinnati and Gesundes Kinzigtal.

Design/methodology/approach - Following the realist methodology, this explorative comparative casestudy investigated PHM initiatives' key features and participants' experiences of developing such initiatives. A semi-structured interview guideline based on a theoretical framework for PHM guided the interviews with stakeholders (20) from different sectors.

Findings - Five initial program theories important to the development of PHM were formulated: (1) create trust in a shared vision and understanding of the PHM rationale to establish stakeholders' commitment to the partnership; (2) create shared ownership for achieving the initiative's goals; (3) create shared financial interest that reduces perceived financial risks to provide financial sustainability; (4) create a learning environment to secure initiative's credibility and (5) create citizens' and professionals' awareness of the required attitudes and behaviours.

Originality/value - The study highlights initial program theories for the implementation of PHM including different strategies and structures underpinning the initiatives. These insights provide a deeper understanding of how large-scale transformation could be developed.
\end{abstract}

Keywords Realist evaluation, Cross-sector partnerships, International comparison PHM initiatives,

Population health management

Paper type Research paper

(C) Betty Steenkamer, Esther de Weger, Hanneke Drewes, Kim Putters, Hans Van Oers and Caroline Baan. Published by Emerald Publishing Limited. This article is published under the Creative Commons Attribution (CCBY 4.0) licence. Anyone may reproduce, distribute, translate and create derivative works of this article (for both commercial \& non-commercial purposes), subject to full attribution to the original publication and authors. The full terms of this licence may be seen at: http://creativecommons.org/ licences/by/4.0/legalcode

This study was only possible because of the participation of four prominent PHM initiatives. We would like to thank the directors and staff members who participated in the interviews, provided feedback and facilitated data collection.

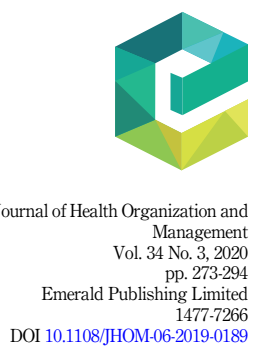

Received 1 February 2019

Revised 15 October 2019

16 January 2020

25 February 2020

Accepted 28 February 2020 
JHOM 34,3

\section{Introduction}

The term "Population Health Management" (PHM) refers to the large-scale transformation efforts required for the reorganization and integration of services across public health, health care, social care and community services, in order to improve population health and the quality of care, while at the same time reducing costs growth (Triple Aim (TA)) (Steenkamer et al., 2017). In different countries, a wide range of organizations spanning different sectors including the health and care sector and other sectors such as the housing-, educational- and business sectors, are working together to design PHM initiatives and implement strategies addressing the wider determinants of health (personal, social, economic and environmental factors impacting populations' health) (Mcgovern et al., 2014). Due to the broad scope and aims of PHM initiatives, such organizations often adopt place-based models in order to implement more integrated and cross-sectoral strategies for the intended population (Fraze et al., 2016; Siegel et al., 2018).

A wide variety of such models have been described in previous studies, e.g. Siegel et al., 2018; Fraze et al., 2016; Mongeon et al., 2017. For example, the World Health Organisation has evaluated the Healthy City program adopted by cities all over the world (De Leeuw, 2012). Similarly, in Europe new PHM models are being evaluated such as Gesundes Kinzigtal in Germany (Pimperl, 2017), the PHM pioneer sites in the Netherlands (Drewes et al., 2016) and the sustainability and transformation partnerships (https:/www.england.nhs.uk/integratedcare/ stps/view-stps/) and City Deals in the United Kingdom (UK), e.g. Manchester Devolution (http:// www.gmhsc.org.uk/about-devolution/).

While previous studies have described the "what" of PHM initiatives - e.g. the type of governance structures implemented or financial arrangements made (Hester, 2018; Matthews et al., 2017) - they have not compared (international) PHM initiatives to understand "how" large-scale transformation of services across (public) health and social care and wider public services is being implemented. Such a comparison may lead to better insight regarding which strategies enable the successful development of PHM initiatives within different contexts. Furthermore, a deeper understanding of participants' reasoning and behaviour is necessary as it is people and not structures that give meaning to the development of PHM (Glasgow et al., 2012; Dickinson, 2014; Rhodes, 2014). Specifically, PHM initiatives may be successful in certain settings and not in others, because the mechanisms, i.e. the reasoning and behaviour of people needed for success are triggered to a different extent in different contexts (Jagosh et al., 2013). Because PHM is still in a relatively early development stage, it is difficult to know how PHM initiatives are impacting population health outcomes. This study therefore examines how local policymakers and senior managers from four different countries expected their strategies to contribute to PHM and what their key learnings were to date. The aim of the study was to generate initial program theories about the development of PHM initiatives. The program theories and underlying strategies, contextual factors and mechanisms that influence PHM initiatives' development are important lessons learnt to consider for the successful implementation of PHM. This study addressed the following research question.

$R Q 1$. What initial program theories describe the development of PHM: what are the PHM strategies, contextual factors and mechanisms that influence PHM development?

\section{Methods}

This exploratory study applied a realist evaluation methodology. A key aspect of the realist methodology is the supposition that initiatives work differently in different contexts (Pawson, 2006; Wong et al., 2017). From a realist point of view, strategies offer or deduct opportunities or resources (e.g. information, skills, resources) within a certain context (Wong 
et al., 2017). How involved people, due to the resources and opportunities available to them in this context change their reasoning or behaviour, influences the outcomes of these strategies (Pawson, 2006; Wong et al., 2017). In order to examine which strategies work, how and why, the authors explored the impact that interactions between the applied strategies $(S)$, contextual factors $(C)$ and mechanisms $(M)$ had on PHM development (i.e. the outcomes, $O$ ) (see Table 1 for the definitions). Following an iterative process, the authors identified the contextual factors of each initiative and constructed strategy-context-mechanism-outcome (SCMO) configurations. Further information about the realist methodology can be found elsewhere (Best et al., 2012; Wong et al., 2017; Saul et al., 2013).

\subsection{Sample}

The research team aimed to select PHM initiatives from different countries. The team discussed initiatives that were described in two recent reviews on PHM (Steenkamer et al., 2020; Hendrikx et al., 2016) (total $N=61$ ). Ultimately, four initiatives were chosen because they were deemed exemplary in terms of their collaboration across a wide range of stakeholders, including the health care sector, social care sector and wider public services. Furthermore, initiatives were also required to be innovative in one or more of the following criteria:

(1) Engaging and collaborating with other sectors including e.g. private and not-forprofit sector including the housing sector, educational institutions, (local) businesses with the aim of reorganizing and integrating public sector services across the different sectors and thus achieve the TA;

Strategy

Context

Mechanism

Outcome

Strategy-context-mechanism-outcome (SCMO) configurations

(Initial) program theories
Refers to intended plans and/or actions Jagosh et al. (2013). In this study, strategies relate to the reorganization and integration of public health, health care, social care and community services, including "partner sectors" (e.g. housing, economic development, transport)

Pertains to the "backdrop" of PHM initiatives Jagosh et al. (2013), i.e. the pre-existing circumstances in which the strategies are implemented (e.g. the different multilevel sociocultural, relational, economic, political or historical factors Glasgow et al. (2012)

Refers to the generative force that leads to outcomes and highlights changes in stakeholders' reasoning and behaviour triggered by changes in contexts; specifically, how and to what extent stakeholders used resources to try and effect change Best et al. (2012)

Refers to (un)intended process outcomes achieved (or expected to be achieved) through strategies implemented within PHM initiatives Jagosh et al. (2013). Process outcomes are e.g. changes in knowledge, attitudes, behaviour, policies or organizational structures

SCMO configurations are heuristics that portray the relationships between strategies, contexts, mechanisms and outcomes; used to understand why strategies work or not in certain contexts (Haynes et al., 2018). SCMOs are used to generate or refine (initial) program theories

Are hypotheses about how a program (component) may or may not work, under what circumstances, and with what outcomes. A program theory therefore hypothesizes how a program (component) is expected to work, given contextual influences and underlying mechanisms (Pawson and Tilly, 1997; Jagosh, 2019)
A study in population health management \\ 275}


JHOM 34,3
(2) Data infrastructure covering multiple sectors and

(3) Innovative contracts and financial arrangements covering multiple sectors.

The following four initiatives were chosen.

(1) Generation Health (GEN-H) in the US;

(2) Greater Manchester Devolution (GM) in the UK;

(3) Vancouver Healthy City Strategy (VHCS) in Canada and

(4) Gesundes Kinzigtal (GK) in Germany.

The contextual differences between the initiatives (e.g. their background including the development stage) highlight the different ways in which PHM can be realized (see Tables 25 for details).

Ethics approval for this study was provided by Tilburg University (EC-2017-79). Purposive sampling was conducted to ensure diversity in initiatives' stakeholders, which ensured insight into a broad range of overarching perceptions and experiences. All contacted participants - i.e. CEOs from private sector organizations (4), practitioners include nurse and general practitioner (2), senior managers from e.g. health care insurer (1), health and social care providers (5), municipalities (2), initiatives' governance structures (4), non-profits (2), agreed to be interviewed (see Tables 2-5 for further information). In total, 20 stakeholders provided consent and were interviewed in 18 interviews - six participants from GEN-H, five participants from GM, five participants from VHCS and four participants from GK. Sixteen interviews were conducted via telephone and two interviews were conducted in person. A semi-structured interview guide was used to anchor the interview process (available upon request).

To ensure all different aspects that could influence PHM development were included in the guide, the CAHN theoretical framework was used which highlights the key components for PHM (i.e. relations, social forces, accountability, leadership, resources, finance, regulations, market) (Steenkamer et al.). All interviews were audio recorded and transcribed. Furthermore, in preparation, initiatives' websites and published papers concerning the initiatives were studied. In addition, participants from each of the case studies sent additional documentation providing further background information on the initiatives, thus further explaining participants' intervention logic. The documents included: three strategic plans (2014; 2017; 2018) from GEN-H, three strategic plans (2015; 2016; 2017) and memorandum of understanding (MoU) 2015 from GM, one evaluation report (2017), three strategic plans (initiation 2014; action 2015; innovation 2016, ) and MoU 2013 from VHCS and two published case-study papers and two evaluation reports (2016; 2018) from GK.

\subsection{Data extraction and data analysis of the interviews}

Applying the realist evaluation approach, the authors constructed SCMO configurations from the interview transcripts in order to examine which PHM strategies, contextual factors and mechanisms influenced the PHM initiatives' development. After the initial drafting of the SCMO configurations, they were then discussed and refined within the research team through multiple rounds of feedback. Afterwards, the authors thematically clustered the SCMO configurations according to strategies and their outcomes, while examining the causal links between the underlying contextual factors and mechanisms - thus examining interviewees' experiences and perceptions and their own ideas of causation related to the development of their PHM initiatives. The thematically clustered SCMO configurations were then corroborated and supplemented with the retrieved documentation, which allowed the authors to more clearly understand and compare the contextual differences and explore how 


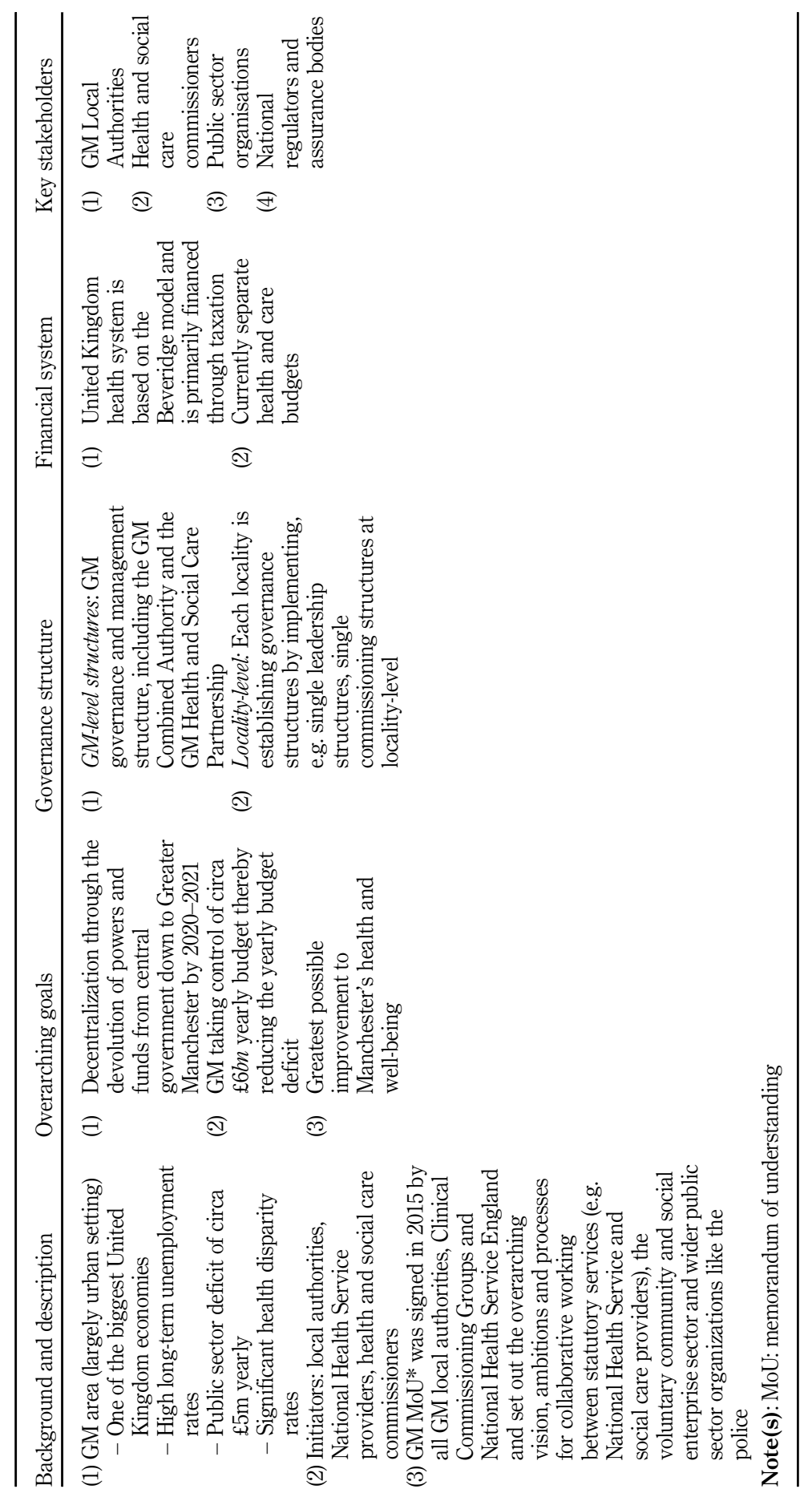

A study in population health management

277

Table 2. Sample summary Greater Manchester (GM) 
JHOM
34,3

278

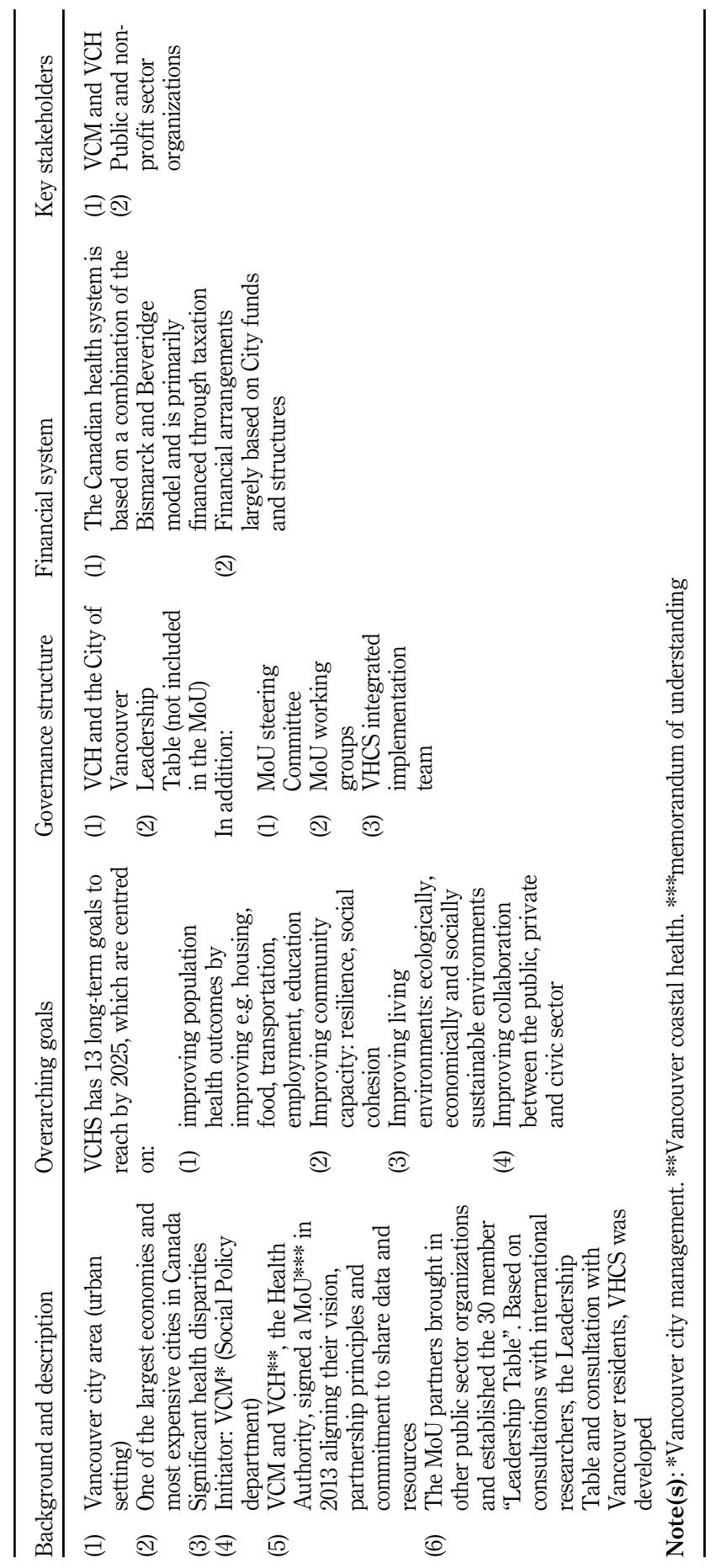

Table 3.

Sample summary

Vancouver Health City Strategy (VHCS) 


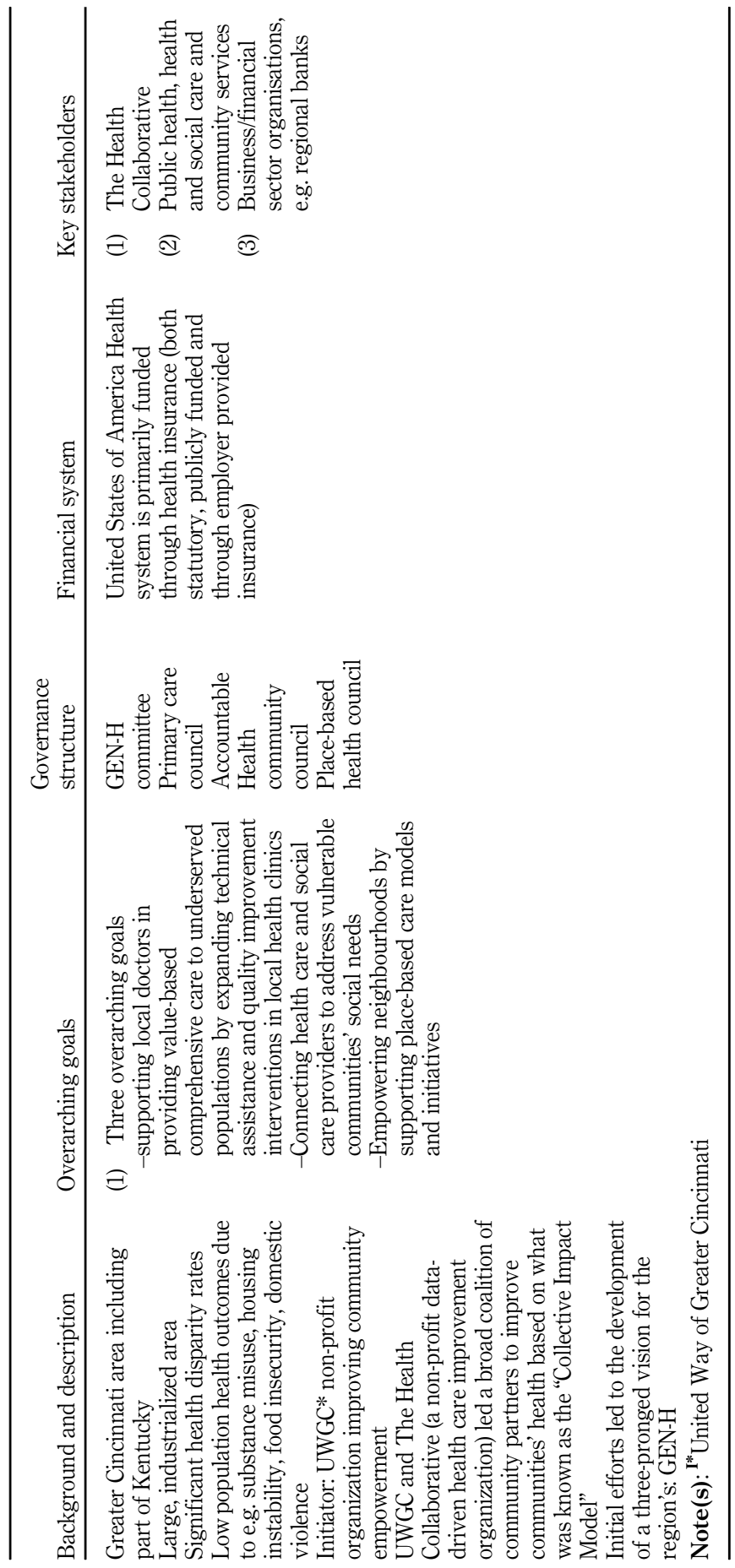




\section{JHOM \\ 34,3}

280

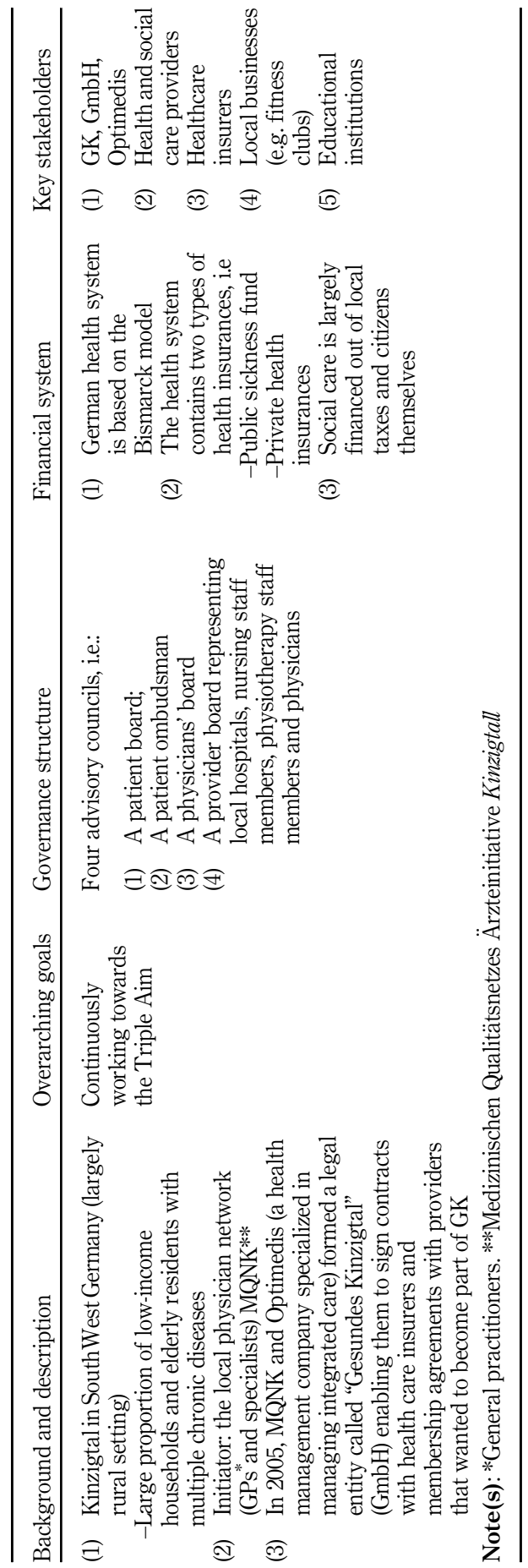

Table 5.

Sample summary

Gesundes

Kinzigtal (GK) 
and why strategies were implemented within those contexts and how such changes triggered the corresponding mechanisms. Based on the thematic clusters, five initial program theories were formulated. The individual SCMO configurations therefore underpin each of the five overarching program theories.

The key features of the PHM initiatives are described in Tables 2-5 and an overview of initiatives' initial contexts is available upon request. In the results section below, the initial program theories will be described (see Tables 6-10) (an overview of all identified SCMOs is available upon request).

\section{Results}

The following section describes per program theory how, according to the interviewees, PHM initiatives developed. The section below will compare the four initiatives per program theory, highlighting the different structures and strategies underpinning the initiatives and why these may work or not in certain contexts.

\subsection{Create trust in a shared vision and understanding of the PHM rationale to establish stakeholders' commitment to the partnership}

This initial program theory highlights the importance of investing in the "softer" aspects of PHM development, i.e. through facilitating trust in a shared vision and understanding of the underlying rationale of the initiative, in order to achieve commitment to the partnership. Initiatives' sense of urgency provided the initial momentum to enter into partnerships to improve population health outcomes (all 4), to address the socio-economic disparities (GM, VHCS, GEN-H) and environmental issues (VHCS) impacting health outcomes. In each of the initiatives, interviewees suggested that stakeholders' commitment to the partnership was based on trust in a shared vision and understanding of the rationale for the partnership (see Table 6 for examples of SCMOs underpinning program theory 1). Comparing the four initiatives, the way trust and understanding were facilitated differed due to differences in initiatives' strategies and contextual factors. GEN-H and GK delegated the gaining of regional stakeholders' commitment to convening organizations to set out the regional vision and goals for the partnership. Whereas GM and VHCS introduced governance agreements based on a previously developed overarching vision and processes for collaborative working. However, GM and VHCS interviewees stated that governance agreements were not enough to secure commitment to the partnership (see Table 6). While GM and VHCS had both implemented a MoU, the MoU in VHCS was limited to the City and the Health Authority. This had a negative effect on the Leadership Table's commitment during the implementation phase, whereas they had been committed during the initial planning phase, as they had bought into the healthy city strategies' vision and goals because of the compelling narrative for change and collaboration. For GEN-H and GK, who did not have formal governance agreements to establish commitment to the partnership like the MoUs in GM and VHCS, stakeholders' co-creative interaction to come up with the best evidence-based model for change, was seen as an important enabling contextual factor in raising stakeholders' understanding e.g. regarding effective interventions.

\subsection{Create shared ownership for achieving the initiatives' goals}

Governance and management structures are required to achieve a sense of shared ownership. This initial program theory highlights the importance of underpinning a shared sense of ownership for achieving the partnerships' regional goals with governance and management structures that provide clear communication channels and clarity about roles and functions. All four initiatives were working towards regional responsibility supported 
JHOM
34,3

282

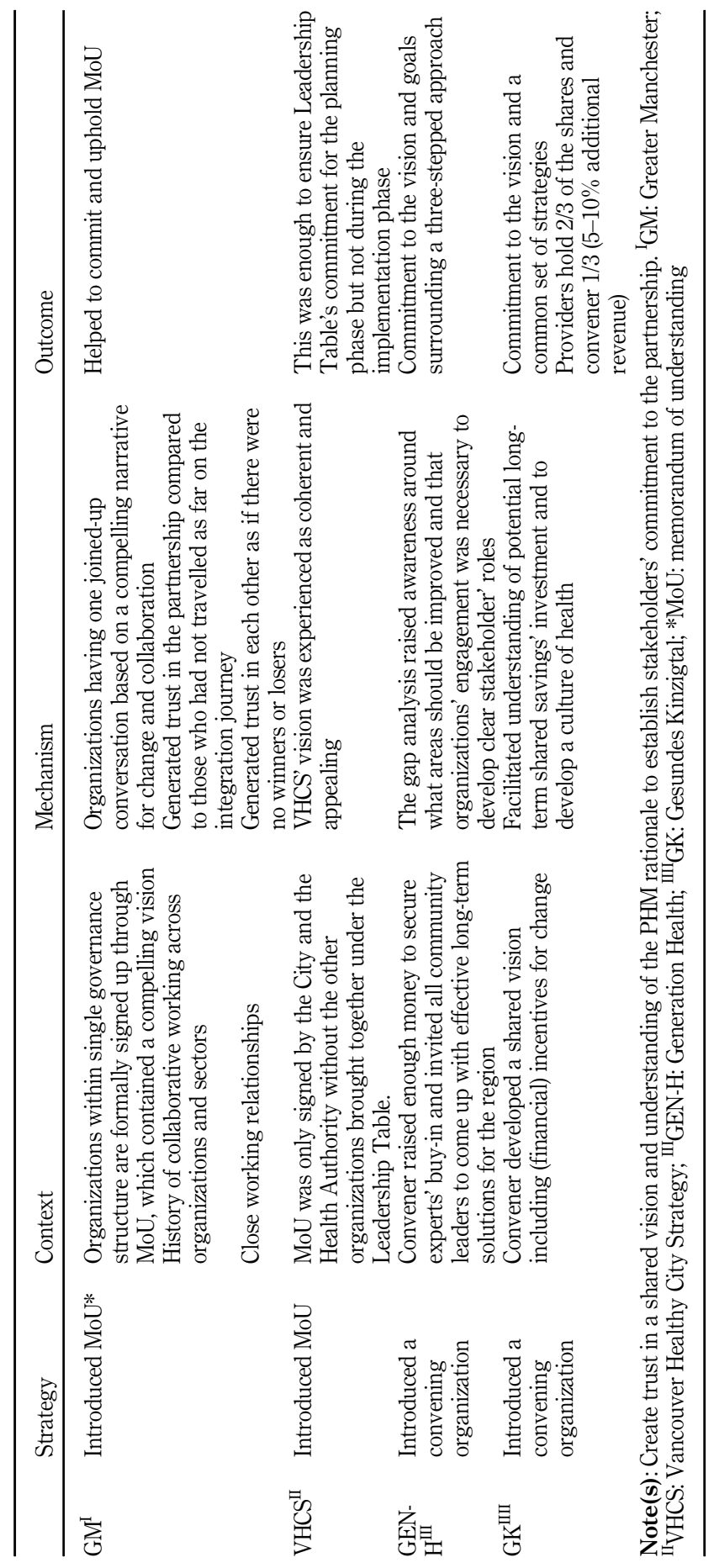

Table 6.

Initial program theory 1 


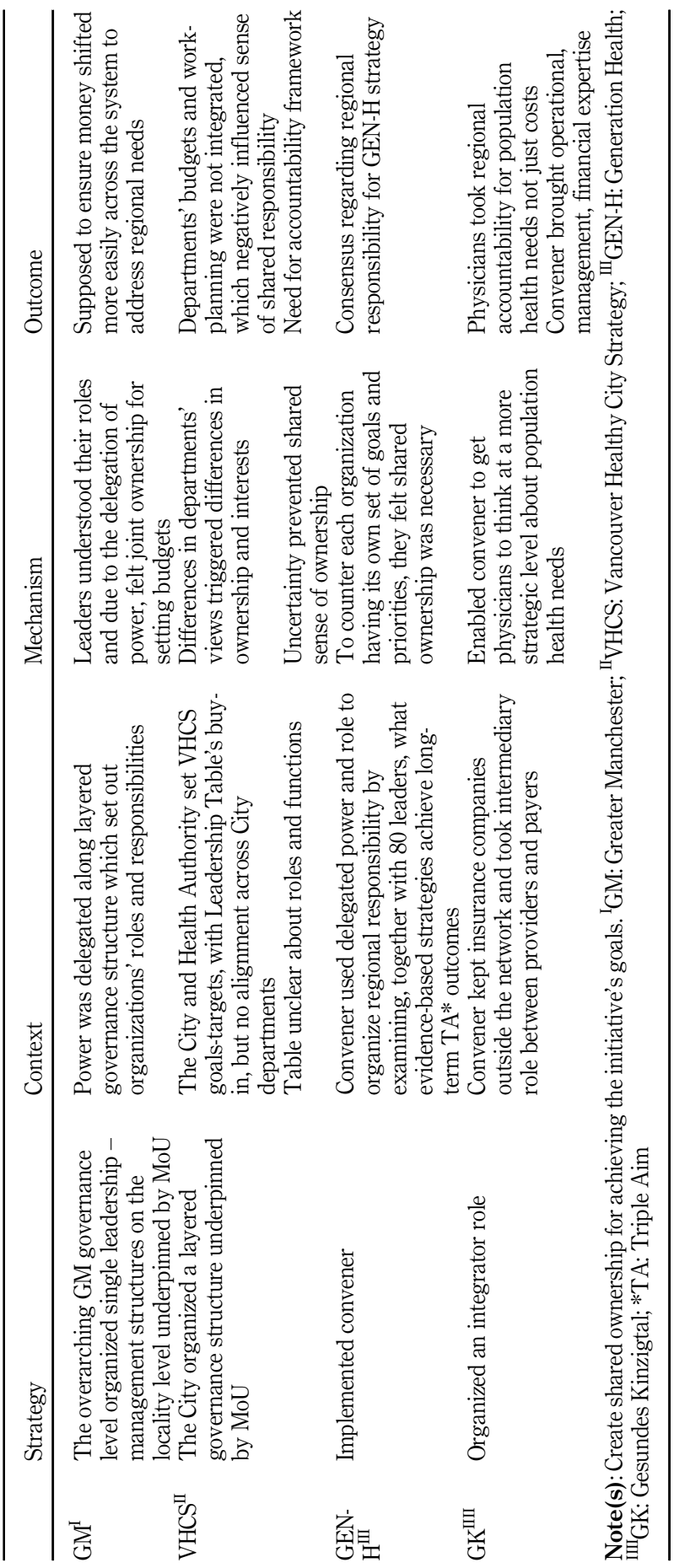

A study in population health management

283

Table 7. Initial program theory 2 
JHOM

34,3

284 $\mid$

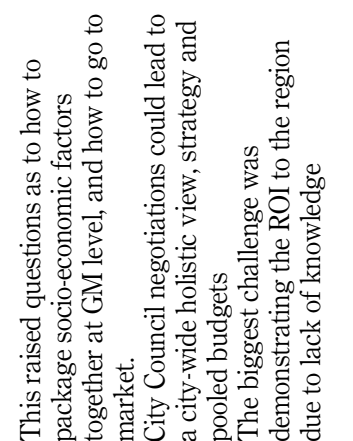

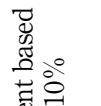

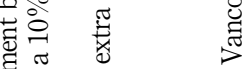

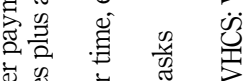

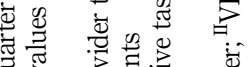

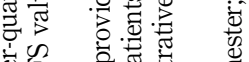

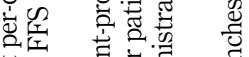

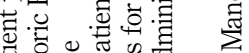

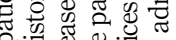

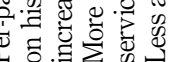

离

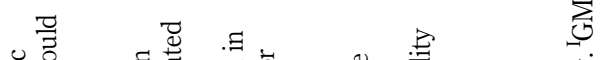

宽里

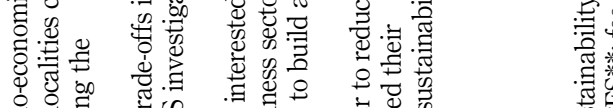

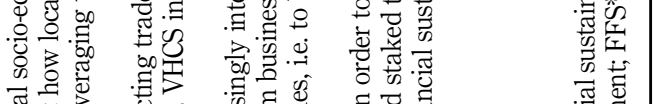

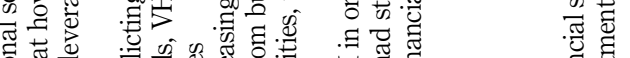

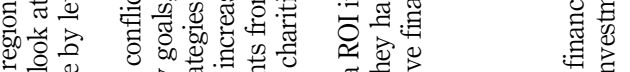

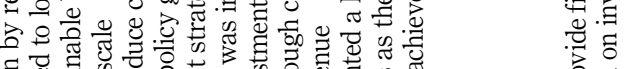

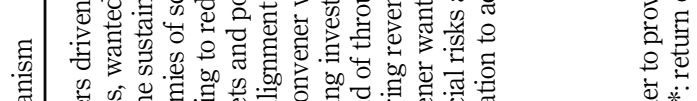

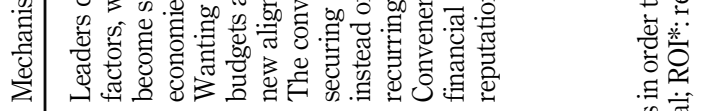

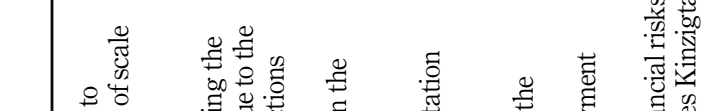

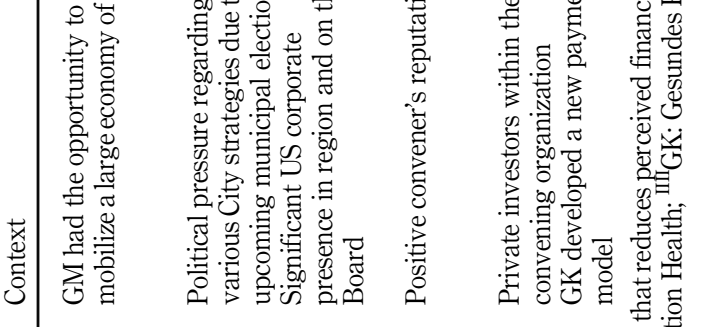

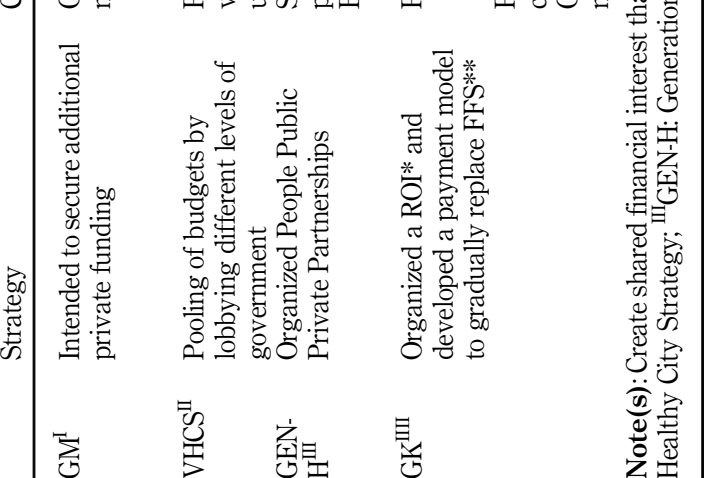

Table 8.

Initial program theory 3 


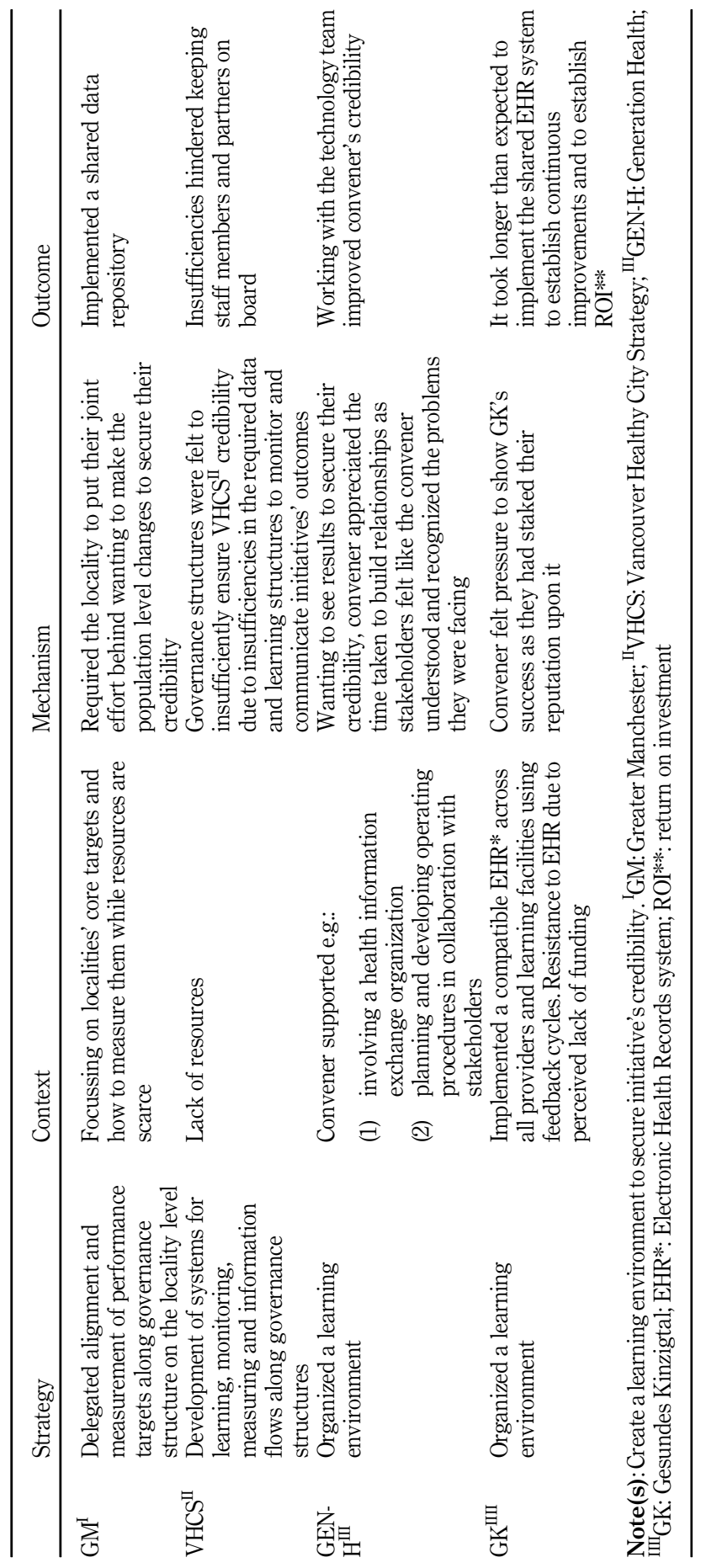

A study in population health management

285

Table 9. Initial program theory 4 
JHOM
34,3

286

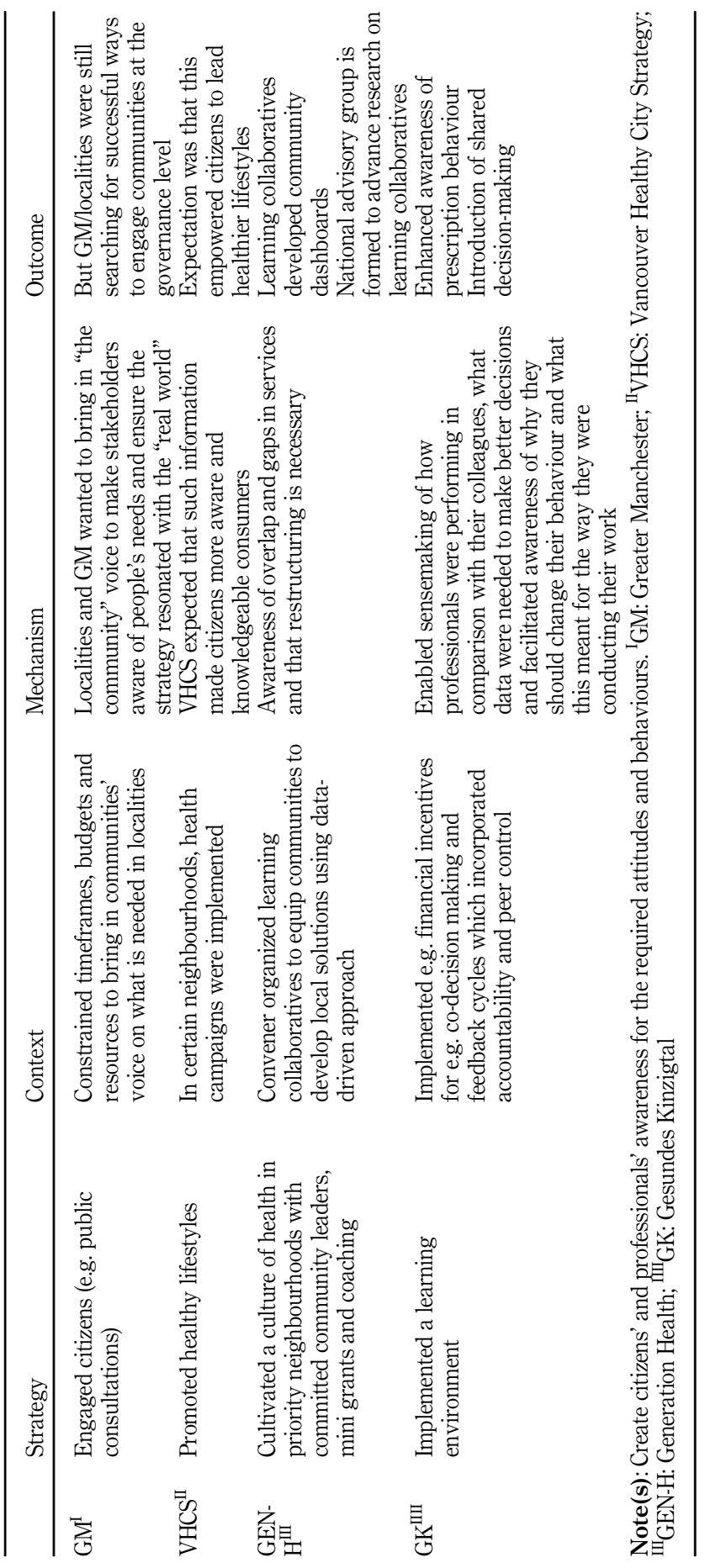

Table 10.

Initial program theory 5 
by structures and processes that motivate, sanction and incentivize adherence to agreed upon goals on a regional level (see Table 2-5). In all initiatives, the effectiveness of governance structures to embed stakeholders' responsibility was affected by a shared sense of ownership, which in turn influenced the extent to which stakeholders shared regional responsibility. However, bearing in mind that initiatives differed in the scale, scope and breadth of their aims, the form in which regional responsibility was embedded and underpinned by governance structures and management processes differed between initiatives. For instance, GM was implementing its PHM plans within the framework of devolving power from the UK National Government to Greater Manchester (decentralization), while GK did so within the framework of establishing accountable care. GM and VHCS had both delegated power along a layered governance structure (see Table 7). Whereas in GEN-H and GK the power to achieve regional responsibility for the TA was delegated to neutral and trusted convening organizations, which were known for their leadership, expertise and workforce capacity. Interviewees thought conveners would be able to engage stakeholders and knowledge institutions, raise ongoing funds, and ensure that funders' rules and guidelines would be properly followed. Furthermore, across the initiatives, different contextual factors played a role in triggering a shared sense of ownership and responsibility (see Table 7). In GM, the delegated power to the GM localities and clarity about roles and functions stipulated within the MoU encouraged a sense of ownership for sharing responsibility. In comparison, in VHCS the layered governance structures were placed under the City's purview. Despite stakeholders' enthusiasm for VHCS, some internal and external stakeholders doubted whether the City was the right driver to organize shared responsibility to further develop VHCS. For instance, within City management, the different departments saw VHCS either as an overarching strategy or as an additional strategy which could be leveraged to support the departments' separate and already existing agenda's (see Table 7). This uncertainty increased when VHCS transitioned from the planning phase to the implementation phase. Because the City had poorly marked and communicated this transition, there was disconnection within the Leadership Table and between the upper tiers of the VHCS structures and those doing the work. VHCS interviewees stated that this lack of leadership had led to their experienced lack of clarity in roles and responsibilities and had in their view highlighted the need for appropriate structures and processes that would link the governance structures, management and implementation processes and goals. In comparison, within GEN-H and GK, the convening organizations actively used the power, role and function delegated to them to organize regional responsibility.

\subsection{Create shared financial interest that reduces perceived financial risks to provide financial sustainability}

This initial program theory highlights the importance of establishing financial sustainability for place-based initiatives by implementing strategies that trigger a shared financial interest. Within the four initiatives, shared financial interests were based on organizations' desire to share or reduce financial risks or gain financial benefits. Each initiative aimed to better financially support the place-based models by: (1) securing additional funding (all initiatives) and aligning budgets across different financial systems (GM, GK, VHCS) and (2) developing alternative payment models (GK, GEN-H). While the alternative payment models were limited to the care sector, funding concerned the pooling of budgets across multiple sectors.

Firstly, initiatives tried to secure additional funding by applying for public funding from federal-national or state-, regional government agencies. In all cases, the funding was not enough to finance initiatives completely. Initiatives therefore also concentrated on gaining additional private funding through public-private partnerships. Contextual factors enabling
A study in population health management

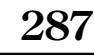


JHOM 34,3

288

such partnerships included the mobilizing of the larger economies of scale (GM, VHCS), the corporate presence in the region (GM, VHCS, GEN-H) and private investors within the convening organizations themselves (GEN-H, GK) (see Table 8 for additional enabling contextual factors). For instance, not being able to leverage the larger economies of scale, GEN-H's convener instead used the strong Fortune 100 presence in the region, and the convener's positive reputation in Cincinnati to encourage regional leaders to invest in GEN-H' interventions not only through the charitable side but also through the business side. By attracting investments through the private sector, GEN-H hoped to build a recurring revenue. For instance, GEN-H was exploring the possibility of entering into a public private partnership to lower the costs of oncology care.

Secondly, GM and VHCS also tried to pool budgets across different financial systems. The pooling of budgets was not only intended to make it easier to shift or share resources across systems but also to encourage organizations to invest in each other for the benefit of the entire region and to improve everyone's capacity to deliver good quality care and support. Interviewees suggested that the success of this strategy may in part depend on whether leadership stimulated the alignment of budgets across the region. For instance, VHCS lobbied at different levels of government to pool policies and budgets, thus enabling health and care providers (and partners from other sectors, including e.g. the non-profit sector) to work more closely together to achieve the initiative's broad aims (see Table 8). Internally, the pooling of budgets across different municipal departments became a more visible issue with the upcoming municipal elections. VHCS was expected to be renewed, as were other citywide strategies such as the Greenest City Action Plan. City teams saw the benefit of aligning the different city strategies and were looking to integrate these strategies to reduce conflicting tradeoffs in budgets and policy goals.

In comparison, GEN-H and GK focussed on alternative payment models. The conveners' support for continuous improvements and the need to achieve a ROI in the public-private partnership investments in order to achieve financial stability, encouraged the initiatives to reduce financial risks. For instance, GK's interviewees said they had previously encouraged value-based activities, such as goal setting agreements between doctors and patients via addon payments. Recently, they had started replacing the fee-for-service payment model for physician practices with a newly developed model that would provide a per-patient perquarter payment. According to the interviewees, the new model simplifies payment and reduces the amount of administrative tasks for physicians', partly because it is supported by an evaluation and performance management system that included an Electronic Health Record system, management reviews and the peer reviewing of patient outcomes. Gradually implementing these strategies in a learning environment (see initial program theory 4) that provided insight into claims and Electronic Health Record data in combination with the convener's wish to establish efficiencies, i.e. in light of investments made by the convener, had according to GK's interviewees, ensured a ROI and the support of investments in and stability for the planning of health interventions.

\subsection{Create a learning environment to secure initiative's credibility}

This initial program theory highlights the importance of establishing continuous improvement cycles by creating a learning environment, i.e. the supportive structures and processes for training, measurement, monitoring and information flows. The initiatives aimed to use learning environments to showcase how initiatives were improving outcomes thus hoping to secure initiatives' and organizations' credibility. These continuous improvement cycles were used to support both the management and practice level. For example, in VHCS part of the data infrastructure that supported bylaws around urban (re) design was kept under the city's sphere of influence. GEN-H and GK's conveners introduced 
training to support the professional level in using the Health Record System. Initiatives' strategies to create continuous improvements that secured initiatives' credibility differed (see Table 9). In addition, in all initiatives, the availability of resources (e.g. training facilities for professionals, expertise, capacity) in light of the scale, scope and aims of the initiatives were important contextual factors that influenced the development of continuous improvement cycles. Having a large scale and broad scope and aims, GM and VHCS delegated the establishment of continuous improvement cycles along the initiatives' governance structures (i.e. VHCS' leadership Table, MoU steering committee and integrated implementation team - GM localities). VHCS and GM interviewees stated they had insufficient resources to develop appropriate systems for training, monitoring and information and data flows across organizations. For example, according to VHCS interviewees, this made it harder for them to monitor and communicate the initiative's progress or to pinpoint where adjustments were required in order to achieve the initiative's goals. This in turn made interviewees feel that it was more difficult to secure the initiative's credibility. Compared to GM and VHCS, for GK and GEN-H the role and function of conveners as supporting organizations was the reason they were chosen in the first place (see also program theory 2). GK's and GEN-H's conveners made continous improvement cycles a specific priority, partly because of their expertise in and capacity for data-management systems and in establishing learning collaboratives. Consequently, as conveners wanted to secure their credibility, by showing initiatives' success as soon as possible, they supported initiatives' data-driven approach, trained the implementation staff members and ensured funding guidelines were being followed.

\subsection{Create citizens' and professionals' awareness of the required attitudes and behaviours}

This initial program theory highlights the importance of investing in professionals' awareness regarding the need to collaborate across sectors (and with communities) and in citizens' awareness of, for instance, healthy lifestyles, to ultimately change behaviours and enable improvements in TA outcomes. The aim of investing in professionals' awareness was to change organizational cultures and to drive efficiencies in care delivery, while the aim of investing in citizens' awareness was to ensure citizens became more knowledgeable consumers of health services and communities' voices were better reflected within initiatives (see Table 10). Initiatives' strategies were aimed at changing attitudes and behaviour at both the community and the organizational levels. Interviewees suggested that various contextual factors enabled the process of sensemaking, such as interactions amongst stakeholders which entailed social pressure to change attitudes and behaviour (e.g. peer reviewing) or bringing in citizens' voices as a means of gaining an understanding of communities' needs (all initiatives), for example, GEN-H, VHCS and GM-enabled interaction between community groups, charities/non-profits and businesses. Interviewees thought this would make representatives of these different sectors more aware of their own responsibilities and highlighted the resources that could be brokered, shared and negotiated. As a result, initiatives identified overlap and gaps in services, which in turn opened up possibilities to change ways of working for instance from working as individual organizations for the community to working in co-creation with the community.

Furthermore, initiatives also pointed out strategies, which had been implemented with the aim of empowering patients and communities in order to improve communities' health and well-being. For example, GK, GEN-H and VHCS had actively invested in public campaigns on topics such as healthy eating, physical activity using the initiative as the platform for health and healthy communities. According to the interviewees, these events "empowered" people, as they, supposedly, became more knowledgeable consumers of health and care services.
A study in population health management

289 
JHOM 34,3

290

\section{Discussion}

This explorative comparative case study investigated key features of four PHM initiatives in four different countries. Additionally, the study explored participants' experiences regarding the implemented PHM strategies and examined the contextual factors and mechanisms that influenced the outcomes of these strategies. The study identified five initial program theories important to the development of PHM, namely:

(1) Create trust in a shared vision and understanding of the PHM rationale to establish stakeholders' commitment to the partnership;

(2) Create shared ownership for achieving the initiative's goals;

(3) Create shared financial interest that reduces perceived financial risks to provide financial sustainability;

(4) Create a learning environment to secure initiative's credibility and

(5) Create citizens' and professionals' awareness of the required attitudes and behaviours.

This is the first study to compare the implementation of four different international PHM initiatives and to understand the SCMOs underlying each program theory, i.e. the specific strategies employed in four international PHM initiatives and the conditions under which these strategies (were expected to) produce(d) certain (process) outcomes. Furthermore, the initial program theories also summarize interviewees' most important lessons learnt. While strategies and contextual factors differed between initiatives, the mechanisms underpinning the program theories were largely consistent across the internationally diverse initiatives. This suggests that the five mechanisms identified in this study could be universal and that these mechanisms will need to be triggered for the successful development of PHM, regardless of national context. The idea that these mechanisms are universal is supported by the mechanisms, which are very similar in nature, identified in a five-year research program which monitored the development of nine PHM initiatives in the Netherlands (Van Vooren, 2019).

This international study shows that it is important to secure commitment to the PHM initiatives' vision and goals (Towe et al., 2016; Siegel et al., 2018; Mongeon et al., 2017). To enable such commitment, more formal top-down enforcement of commitment through e.g. MoUs, is not enough to ensure such commitment (Ovseiko et al., 2014; Siegel et al., 2018) A bottom-up approach focussing more on garnering stakeholders' insight into the value of committing to the partnerships' vision and goals is important as well. Our study, in line with the previous literature, highlights that creating a sense of urgency amongst stakeholders is an important factor in garnering stakeholders' commitment (Van Vooren, 2019). Furthermore, the study shows the different ways in which policymakers could stimulate and invest in PHM. Relatedly, the same bottom-up and top-down principle also seems to apply to initiatives seeking to establish regional responsibility for the transformation to PHM initiatives. Increasingly, different countries and national and regional governments stress the need for such transformations. However, how organisations from different sectors should collaboratively take regional responsibility for this transformation remains unclear, specifically what type of care needs to be organized at which level (i.e. national, regional, local) and who can best lead initiatives (Drewes et al., 2018). Our study suggests that an important risk regarding the devolution of powers to newly delegated governance structures involves merely moving fragmentation from the national level to the regional/local level, especially if stakeholders do not solve the original fragmentation issues during the devolution process. While the risk of a gradual approach to achieving cross-sector accountable care lies 
in the difficulty of implementing changes beyond the (health)care sector and for each sector to embrace the ethos of wider determinants of health.

In addition to earlier studies, this study explored how initiatives hoped to improve financial sustainability over longer periods of time with a range of new financial approaches (Song et al., 2014; Lewis et al., 2017). For example, the trusted conveners in this study were willing to take responsibility for the financial risks by financing health services. Many initiatives are exploring private investments to build recurring revenues (Van Vooren, 2019; Mongeon et al., 2017). In the Netherlands for instance, the government has set up a government investment bank called Invest-NL, which aims to financially support and stimulate societal transitions (e.g. towards green energy, efficient health and care, innovative education) (Wiebes et al., 2018). The government wanted to avoid investments made by private investors in PHM initiatives to avoid private investors' influence on stakeholders' behaviour and thus initiative's development (Wiebes, 2018). Further research is necessary to investigate if and how public-private partnerships could be of value and what the consequences would be. The study also showed how initiatives tried to leverage enabling political developments and to mitigate constraining political developments. The need that this study's initiatives had for regional-national policy-department partnerships to establish collective policy and funding efforts, is in line with the previous literature which emphasized the importance of the pursuit of health and well-being through "whole-of-society" approaches as well as "whole-of-government" approaches (Browne et al., 2017; De Leeuw et al., 2014). This international study also showed that shifts in national and regional governments' politics and priorities regarding the public sector more broadly, and the PHM initiatives specifically, can have a significant impact on initiatives' sustainability. For instance, some of this study's UK interviewees suggested the UK government's attention had shifted from devolution to Brexit (the term used to describe the process of the UK exiting the European Union). They anticipated this could make it harder for GM to receive financial and policy support from Westminster. Some participants had also expressed concerns that Brexit, instigated at the national level, might affect the size of the regional workforce available to support the new models. Comparatively, the US interviewees mentioned that despite the expectation that the new federal government might want to invest less in public sector infrastructure and might want to repeal the obama era affordable care act (ACA), the state level government would continue to support the initiative regardless of the different direction they expected the federal government to take. In an effort to safeguard initiatives from such national trends, and to continue improving regional accountability, interviewees mentioned they were exploring the potential of leveraging communities' support for addressing the wider determinants of health. Though community engagement is increasingly seen as a key component of place-based models (De Weger et al., 2018) - with the assumption that involving communities can help ensure services are more tailored to their needs - the four initiatives remained unsure of how to engage communities more meaningfully.

Interestingly, throughout the program theories, the scale, scope and breadth of initiatives' aims seemed to be linked to who initiated the PHM initiatives and the key stakeholders, which in turn influenced how PHM initiatives developed, e.g. the form in which regional responsibility was embedded and underpinned by governance structures and management processes. A relatively large region with a high population number, broad scope and underlying aims tentatively seems associated with the involvement of government authorities and a larger number of stakeholders, in comparison to PHM initiatives where providers were key initiators.

\subsection{Limitations}

This study was exploratory in nature and investigated stakeholders' experiences and perceptions of the development and implementation of four PHM initiatives from four
A study in population health management 
JHOM 34,3 different countries. Despite this limited number, the included initiatives ensured a broad representation of PHM as they excelled in one or more of the characteristics necessary for the development of PHM. In addition, because results depend on which stakeholders were interviewed, this study has not only included initiatives' senior-level representatives and key stakeholders but also ensured a broad representation of the different sectors.

As far as the authors are aware, this is the first internationally comparative study to investigate the SCMOs underlying PHM development. This explorative study has provided insight into the initial program theories and underlying strategies, contextual factors, mechanisms and process outcomes of large-system transformations. To refine these program theories and improve our understanding of PHM initiatives further, longitudinal studies could be carried out, which would include different stakeholders' perceptions and experiences at all levels of PHM initiatives. Such a study could also test whether expected outcomes highlighted above (e.g. empowering citizens by health campaigns is expected to contribute to healthier lifestyles) were indeed achieved.

Furthermore, to deepen our understanding, future studies could examine which strategies within the five program theories should be implemented in the different PHM's developmental phases (Erickson et al., 2017), to ensure PHM initiatives' successful development. Additionally, studies should investigate if and how initiators influence organizational processes, cultures and stakeholders' behaviours. Future studies are needed to further explore and confirm this potential finding. Furthermore, PHM initiatives increasingly seem to be emblematic of trends towards regionalization and decentralization. As the findings seem to suggest that the development of PHM initiatives is influenced by who initiates the initiatives, future research could investigate how much power and funding should be passed down from national governments down to the local-level and which roles and functions should remain at the national level and which roles could be taken up by regional or local governments. Furthermore, future studies could explore how local areas should use regional accountabilities and powers and how such initiatives could be better incentivized by policies that fully support cross-sector collaboration in order for place-based initiatives to address the wider determinants of health.

\section{Conclusions}

The study highlighted five initial program theories and described the underlying conditions which influenced the development of four international PHM initiatives. These program theories and the underlying contextual factors and mechanisms indicate important lessons learnt for policymakers and program managers to bear in mind when developing PHM initiatives. It is important for future studies to keep providing insight into the development of PHM initiatives in order to better understand which PHM strategies need to be implemented and what contextual factors and mechanisms need to be triggered.

\section{References}

Best, A., Greenhalgh, T., Lewis, S., Saul, J.E., Caroll, S. and Bitz, J. (2012), "Large-system transformation in health care: a realist review", Milbank Quarterly, Vol. 90 No. 3, pp. 421-456.

Browne, J., De Leeuw, E., Gleeson, D., Adams, K., Atkinson, P. and Hayes, R. (2017), "A network approach to policy framing: a case study of the national aboriginal and torres strait islander health plan", Social Science and Medicine, Vol. 172, pp. 10-18.

De Leeuw, E. (2012), "Evaluating WHO healthy cities in Europe: issues and perspectives", Journal of Urban Health, Vol. 90, pp. 1-23. 
De Leeuw, E., Tsouros, A.D., Dyakova, M. and Green, G. (2014), Healthy Cities: Promoting Health and Equity - Evidence for Local Policy and Practice, WHO Regional Office for Europe, Copenhagen.

De Weger, E., Van Vooren, N., Luijkx, K.G., Baan, C.A. and Drewes, H.W. (2018), “Achieving successful community engagement: a rapid realist review", BMC Health Services Research, Vol. 18 No. 1, p. 285.

Dickinson, H. (2014), "Making a reality of integration: less science, more craft and graft", Journal of Integrated Care, Vol. 22 Nos 5/6, pp. 189-196.

Drewes, H.D., Van Vooren, N.J.E., Steenkamer, B.M., Kemper, P.F., Hendrickc, R.J. and Baan, C.A. (2018), Regio's in Beweging Naar Een Toekomstbestendig Gezondheidssysteem: Landelijke Monitor Proeftuinen-Reflectie Op 5 Jaar Proeftuinen, RIVM, Bilthoven.

Drewes, H.W., Struijs, J.N. and Baan, C.A. (2016), "How the Netherlands is integrating health and community services", NEJM Catalyst, available at: https:/catalyst.nejm.org/netherlandsintegratinghealthcommunity-services/.

Erickson, J., Milstein, B., Schafer, L., Evans-Pritchard, K., Levitz, C., Miller, C. and Cheadle, A. (2017), Progress along the Pathway for Transforming Regional Health: A Pulse Check on Multi-Sector Partnerships, Robert Wood Johnson Foundation and the Rippel Foundation.

Fraze, T., Lewis, V.A., Rodriguez, H.P. and Fisher, E.S. (2016), "Housing, transportation, and food: how ACOs seek to improve population health by addressing nonmedical needs of patients", Health Affairs, Vol. 35 No. 11, pp. 2109-2115.

Glasgow, R.E., Green, L.W., Taylor, M.V. and Strange, K.C. (2012), "An evidence integration triangle for aligning science with policy and practice", American Journal of Preventive Medicine, Vol. 42 No. 6, pp. 646-654.

Haynes, A., Rowbotham, S.J., Redman, S., Brennan, S., Williamson, A. and Moore, G. (2018), "What can we learn from interventions that aim to increase policy-makers' capacity to use research? A realist scoping review", Health Research Policy and Systems, Vol. 16 No. 1, pp. 31.

Hendrikx, R.J.P., Drewes, H.W., Spreeuwenberg, M., Ruwaard, D., Struijs, J.N. and Baan, C.A. (2016), "Which triple aim related measures are being used to evaluate population management initiatives an international comparative analysis", Health Policy, Vol. 120, pp. 471-485.

Hester, J. (2018), “A balanced portfolio model for improving health: concept and vermont's experience", Health Affairs, Vol. 37 No. 4, pp. 570-578.

Jagosh, J. (2019), "Realist synthesis for public health: building an ontologically deep understanding of how programs work, for whom, and in which contexts", Annual Rev. Public Health, Vol. 40, pp. 361-72.

Jagosh, J., Pluye, P., Wong, G., Cargo, M., Salsberg, J., Bush, P.L., Herbert, C.P., Green, L.W., Greenhalgh, T. and Macaulay, A.C. (2013), "Critical reflections on realist review: insights from customizing the methodology to the needs of participatory research assessment", Research Synthesis Methods, Vol. 5, pp. 131-141.

Lewis, V.A., Tierney, K.I., Colla, C.H. and Shortell, S.M. (2017), "The new frontier of strategic alliances in health care: new partnerships under accountable care organizations", Social Science Medicine, Vol. 190.

Matthews, M.R., Miller, C., Stroebel, R.J. and Bunkers, K.S. (2017), "Making the paradigm shift from siloed population health management to an enterprise-wide approach", Population Health Management, Vol. 20 No. 4, pp. 255-261.

Mcgovern, L., Miller, G. and Hughes-Cromwick, P. (2014), "The relative contribution of multiple determinants to health outcomes", [Online], available at: https:/www.healthaffairs.org/do/10. 1377/hpb20140821.404487/full/ (accessed 22 November 2018).

Mongeon, M., Levi, J. and Heinrich, J. (2017), "Elements of accountable communities: a review of the literature", Discussion Paper, National Academy of Medicin, Washington DC. 
JHOM 34,3

Ovseiko, P.V., O'sullivan, C., Powell, S.C., Davies, S.M. and Buchan, A.M. (2014), "Implementation of collaborative governance in cross-sector innovation and eduction networks: evidence from the national health service in England", BMC Health Service Research, Vol. 14, p. 552.

Pawson, R. (2006), Evidence-Based Policy: A Realist Perspective, SAGE Publications, London.

Pawson, R. and Tilley, N. (1997), "Realistic Evaluation", Sage Publishers, London.

Pimperl, A. (2017), "Re-orienting the model of care towards accountrable care organizations", International Journal of Integrated Care, Vol. 18 Nos 1-8.

Rhodes, R.A.W. (2014), "Recovering the craft of public administration in network governance", [Online], available at: www.ispa.org/my-ipsa/events/montreal12014/plenary/plenary-recovering (accessed 22 November 2018).

Saul, J.E., Willis, C.D., Bitz, J. and Best, A. (2013), "A time-response tool for informing policy making: rapid realist review”, Implementation Science, Vol. 8 No. 103, pp. 1-15.

Siegel, B., Erickson, J., Milstein, B. and Evans Pritchard, K. (2018), "Multisector partnerships need further development to fulfill aspirations for transforming regional health and well-being", Health Affairs, Vol. 37 No. 1, pp. 30-37.

Song, Z., Rose, S., Safran, D., Landon, B.E., Day, M.P. and Chernew, M.E. (2014), "Changes in health care spending and quality 4 years into global payment", The New England Journal of Medicine, Vol. 371 No. 18, pp. 1707-1714.

Steenkamer, B., Drewes, H.W., Putters, K., Van Oers, H. and Baan, C.A. (2020), "Reorganising and integrating public health, health care, social care and community services: a theory-based framework for collaborative adaptive health networks to achieve the triple aim", Journal of Health Services Research and Policy, available at: https://doi.org/10.1177/1355819620907359.

Steenkamer, B.M., Drewes, H.W., Heijink, R., Baan, C.A. and Struijs, J.N. (2017), "Reorganizing and integrating public health, health care, social care and wider public services: a theory-based framework for collaborative adaptive health networks to achieve the triple aim", Journal of Population Health Management, Vol. 20 No. 1, pp. 74-85.

Towe, V.L., Leviton, L., Chandra, A., Sloan, J.C., Tait, M. and Orleans, T. (2016), "Cross-sector collaborations and partnerships: essential ingredients to help shape health and well-being", Health Affairs, Vol. 35 No. 11, pp. 1964-1969.

Van Vooren, N.J.E., Steenkamer, B.M., Baan, C.A. and Drewes, H.W. (2019), "Transforming towards sustainable health and wellbeing systems: eight guiding principles based on the experiences of nine Dutch population health management initiatives”, Health Policy, Vol. 11 Nos 37/43.

Wiebes, E. (2018), Memorie van Toelichting Invest-NL, Den Haag, available at: https://www. parlementairemonitor.n1/9353000/1/j9vvij5epmj1ey0/vkly7w43xxtb.

Wiebes, E., Hoekstra, W.B. and Kaag, S.A.M. (2018), "Vormgeving invest-NL", Tweede Kamer der Staten Generaal, Den Haag, available at: https://www.tweedekamer.nl/kamerstukken/brieven_ regering/detail?id 2018Z02696\&did=2018D05432.

Wong, G., Westhorp, G., Greenhalgh, J., Manzano, A., Jagosh, J. and Greenhalgh, T. (2017), Quality and Reporting Standards, Resources, Training Materials and Information for Realist Evaluation: the RAMESES II Project, NIHR Journals Library, Southhampton, UK.

\section{Corresponding author}

Esther de Weger can be contacted at: Esther.de.weger@rivm.nl

For instructions on how to order reprints of this article, please visit our website:

www.emeraldgrouppublishing.com/licensing/reprints.htm

Or contact us for further details: permissions@emeraldinsight.com 